\title{
Cell-mediated immunity to hepatitis B surface antigen in blood donors with persistent antigenaemia
}

\author{
W. M. LEE ${ }^{1}$, W. D. REED, C. G. MITCHELL, I. L. WOOLF, I. W. DYMOCK, \\ A. L. W. F. EDDLESTON, AND ROGER WILLIAMS \\ From the Liver Unit, King's College Hospital and Medical School, London, and the Department of \\ Medicine, University Hospital of South Manchester
}

SUMmary Cellular immunity to the hepatitis B surface antigen (HBsAg) and a liver-specific lipoprotein was studied, using the leucocyte migration test, in 38 asymptomatic blood donors found to have HBsAg in the serum. Sensitization to HBsAg was found in $26 \%$ and was related to the presence of liver damage, being detected in $47 \%$ of those with elevated serum aspartate aminotransferase but in only $13 \%$ with normal enzyme levels. The frequency of sensitization to this antigen in those with chronic persistent or chronic aggressive hepatitis on biopsy was also higher than in those with unrelated or minimal changes. The findings using the liver-specific lipoprotein as antigen were similar and there was a correlation between the results obtained with this and the hepatitis B surface antigen.

This study supports the hypothesis that a T-lymphocyte response to hepatitis B virus antigen can initiate an autoimmune reaction to antigens such as liver-specific lipoprotein on the hepatocyte surface, and that this reaction may be of importance in the production of chronic liver damage. In the absence of the T-cell response, the autoimmune reaction cannot occur and the virus is able to establish a harmless symbiotic union with the host.

The finding of asymptomatic carriers of the hepatitis B surface antigen (HBsAg) has stimulated interest in the interplay between viral and host factors in determining the outcome of infection with the hepatitis B virus. Although the majority of these individuals in a recent series (Woolf, Boyes, Jones, Whittaker, Tapp, MacSween, Renton, Stratton, and Dymock, 1974) showed some evidence of liver damage, there are some carriers with entirely normal liver histology. In these, HBsAg can be shown to be present in many hepatocytes (Hadziyannis, Vissoulis, Moussouros, and Afroudakis, 1972), which has led to the suggestion that the virus may not be cytopathic and that the destruction of infected cells in patients with acute virus B hepatitis and in those with chronic forms of liver damage is due to the development of an immune response to the infectious

'Present address: Department of Medicine, Columbia University College of Physicians and Surgeons, 630 West 168th Street, New York, NY 10032, USA

Received for publication 21 April 1975. agent. Dudley, Fox, and Sherlock (1972) suggested that the persistence of $\mathrm{HBsAg}$ - whether or not liver disease was present-is related to a defect in cellular immunity and they found an impairment in lymphocyte response to phytohaemagglutinin (PHA), a T-cell mitogen, in patients with chronic liver disease and persistent antigenaemia as compared with normal controls (Giustino, Dudley, and Sherlock, 1972). However, Nielsen, Reinicke, Dietrichson, Andersen, Thomsen, and Andersen (1973) showed a normal response to PHA in healthy carriers of HBsAg and concluded than the impaired T-cell response in those with chronic hepatitis was related to the liver disease rather than to the carrier state. Nevertheless, in healthy carriers there could be a more specific defect in the immune response to HBsAg, and the present study was designed to investigate this possibility. Cellular immunity to HBsAg has been examined using the leucocyte migration test in blood donors found to be carriers of the antigen, some of whom had abnormalities on liver biopsy of varying severity. The patients 
were also tested for evidence of sensitization to a liver-specific membrane lipoprotein. This has been shown to be of importance in the progressive liver damage of active chronic hepatitis (Eddleston and Williams, 1974) which in some instances can follow virus $B$ infection.

\section{Subjects and Methods}

The 38 subjects studied had had HBsAg detected in serum previously by immunodiffusion or electrophoresis during routine blood donor screening. They had been referred on this basis to the regional clinic in Manchester for advice and follow up. None had had clinical hepatitis nor had any been on immunosuppressive therapy. Hepatitis B surface antigen had been present in all for at least six months at the time of the study. Selection of subjects from a total population of 160 antigen carriers took place at random at regular clinic visits, except that samples were obtained preferentially from patients in whom a liver biopsy had been performed.

Serum and leucocytes sedimented in dextran and heparin were obtained by one of us (IWD) and transported to King's College Hospital where the immunological studies were carried out on the same day. Confirmation of the screening tests for HBsAg was obtained on the day of study using sensitive radioimmunoassay techniques previously described (Reed, Eddleston, Stern, Williams, Zuckerman, Bowes, and Earl, 1973). The titre of $\mathrm{HBsAg}$ in serum was also determined by a complementfixation test.

The leucocyte migration test using partially purified HBsAg as antigen was performed as previously described (Reed, Mitchell, Eddleston, Lee, Williams, and Zuckerman, 1974) and in 16 patients cell-mediated immunity to a liver-specific lipoprotein was also studied (Eddleston, McFarlane, Mitchell, Reed, and Williams, 1973). On the basis of previous observations, migration indices considered to be normal for this method were 0.80 1.20 for HBsAg and 0.75-1.05 for the liverspecific lipoprotein. The samples were coded and the results correlated with the clinical findings at the end of the study.

\section{Results}

All the 38 patients investigated were asymptomatic, but 15 had an elevated serum aspartate aminotransferase level ranging from 44 to 247 IU/litre. Liver biopsy was performed in 10 of these cases and in seven in whom aminotransferase levels were normal. Some abnormality was found in all biopsies but in two this was considered to be unrelated to the presence of $\mathrm{HBsAg}$ : one, in a patient with a high alcoholic intake, showing some fat deposition in hepatocytes, and the other having small granulomata initially but entirely normal histological appearances on follow-up biopsy. In seven instances only minor parenchymal changes were shown, with small focal areas of hepatocellular necrosis, but in the remaining eight there was an infiltrate of mononuclear cells in portal tracts, three showing changes consistent with chronic aggressive hepatitis and the other five being classified as chronic persistent hepatitis.

Inhibition of leucocyte migration with $\mathrm{HBsAg}$ as the antigen was found in $10(26 \%)$ of the 38 patients tested. Examination of these results in relation to the biochemical and/or histological abnormalities already detailed showed significant correlations (see table). Only three $(13 \%)$ of 23 cases with normal

\begin{tabular}{lllll}
\hline $\begin{array}{l}\text { Serum } \\
\text { Aspartate } \\
\text { Amino- } \\
\text { transferase }\end{array}$ & \multicolumn{2}{l}{ Inhibition of Leucocyte Migration } \\
\cline { 2 - 3 } & \multicolumn{2}{l}{ With HBsAg } & & With LSP \\
\cline { 2 - 3 } \cline { 5 - 6 } & $\begin{array}{l}\text { No. } \\
\text { Tested }\end{array}$ & No. & & No. \\
& Abnormal & Tested & $\begin{array}{l}\text { No. } \\
\text { Abnormal }\end{array}$ \\
\hline Normal & 23 & $3(13 \%)$ & 7 & 0 \\
Abnormal & 15 & $7(47 \%)$ & 9 & $7(78 \%)$ \\
\hline
\end{tabular}

Table Results of the leucocyte migration test with hepatitis $B$ surface antigen and the liver-specific lipoprotein $(L S P)$ in relation to serum aspartate aminotransferase levels

serum aspartate aminotransferase levels showed inhibition of migration, whereas this was present in seven $(47 \%)$ of the 15 with abnormal enzyme levels, a statistically significant difference $(P=0.04$ by Fisher's exact test). Of the nine cases with unrelated changes or focal parenchymal necrosis on liver biopsy, only one $(11 \%)$ showed evidence of cellular immunity to $\mathrm{HBsAg}$ as compared with three $(38 \%)$ of the eight cases with either chronic persistent or chronic aggressive hepatitis. We have previously shown (Lee, Reed, Mitchell, Galbraith, Eddleston, Zuckerman, and Williams, 1975) that it is usually not possible to demonstrate sensitization in vitro when the level of HBsAg in serum is equal to or higher than that used in the leucocyte migration test (approximately $1 / 512$ by complement fixation). This was so in eight of the patients in whom a biopsy had been performed. Migration inhibition could be demonstrated in only one of the six with chronic hepatitis and high titres of antigen, whereas two others, also with chronic hepatitis but low titres of antigen, both showed migration inhibition (fig 1).

In 16 patients who were examined for evidence of sensitization to the liver-specific lipoprotein there 


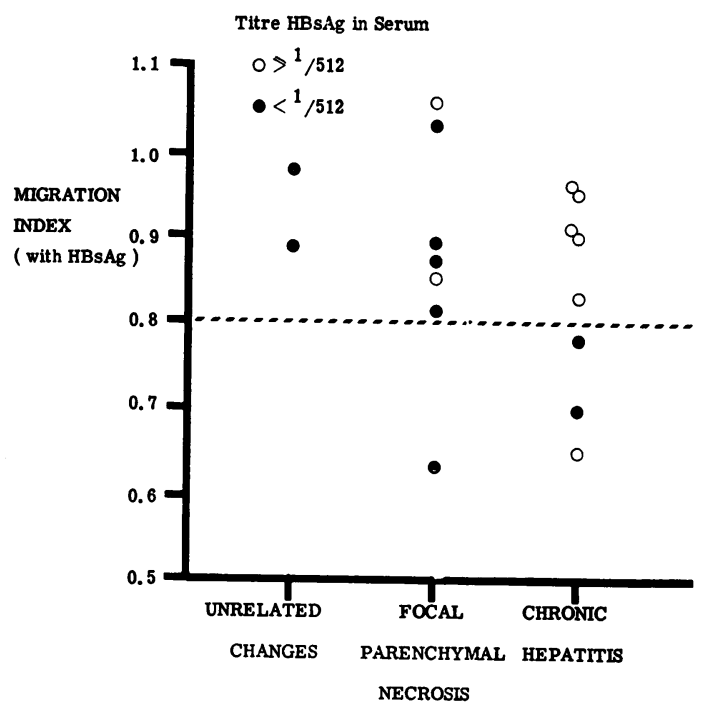

Fig 1 Results of the leucocyte migration test with HBs Ag as antigen in the 17 patients in whom a liver biopsy had been performed. The chronic hepatitis group includes those with histological features of chronic persisient or chronic aggressive hepatitis.

was also a close relationship between the results of the leucocyte migration test and the presence of liver damage (table I and fig 2). Inhibition of migration in the presence of the lipoprotein antigen was observed in seven $(78 \%)$ of nine cases with abnormal serum aspartate aminotransferase levels but was found in

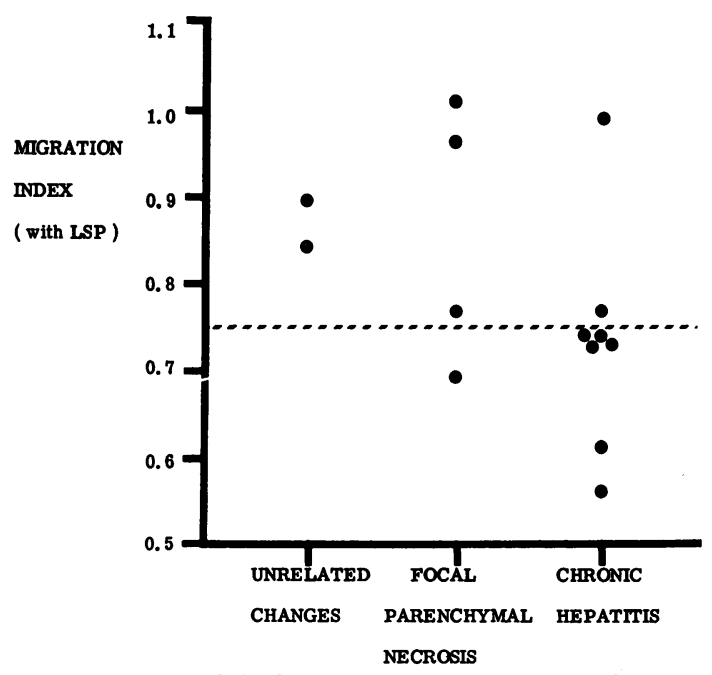

Fig 2 Results of the leucocyte migration test with the liver-specific lipoprotein as antigen in relation to histological changes on liver biopsy. none of seven in whom the enzyme levels were normal, a statistically significant difference $(P=$ 0.003 ). Eight patients had histological evidence of chronic persistent or chronic aggressive hepatitis and inhibition of migration was present in six $(75 \%)$. Of two with unrelated histological changes, both had normal migration indices, and of four with focal parenchymal necrosis only one showed sensitization to the lipoprotein.

Since sensitization to both HBsAg and the liverspecific lipoprotein seemed to be related to the presence of liver damage a correlation might be expected between the migration indices using the two different antigens. This was in fact so in the 16 cases in which leucocyte migration tests with both antigens were carried out at the same time; 12 had normal migration indices with $\mathrm{HBsAg}$, and, of these, nine also had normal results with the lipoprotein antigen. In three of the four with detectable cellular immunity to $\mathrm{HBsAg}$, sensitization to the liverspecific lipoprotein was also demonstrable.

\section{Discussion}

Although $63 \%$ of the patients in this study had normal serum aspartate aminotransferase levels, in only $12 \%$ of those in whom a biopsy had been performed could the presence of HBsAg be shown to be without effect on liver structure. However, most of those with focal parenchymal necrosis also had normal transaminase levels and the prognostic importance of this lesion is unknown. More information is available concerning the likely outcome in those with inflammation in the portal tracts. Progression to cirrhosis is common with chronic aggressive hepatitis but rare if the initial biopsy shows the milder changes of chronic persistent hepatitis (de Groote, Desmet, Gedigk, Korb, Popper, Poulsen, Scheuer, Schmid, Thaler, Uehlinger, and Wepler, 1968).

The low incidence of sensitization to $\mathrm{HBsAg}$ in those cases with normal serum aspartate aminotransferase levels and the absence of a cellular immune response in the two patients without related changes on biopsy are findings which support the hypothesis that there is a specific defect in cellular immunity to $\mathrm{HBsAg}$ in such healthy carriers which allows the hepatitis $B$ virus to establish a harmless symbiosis with the host. The findings in those with evidence of liver damage were quite different, almost half the cases with a serum aspartate aminotransferase elevation showing sensitization to HBsAg. The interpretation of the results in those with proven chronic persistent or chronic aggressive hepatitis is difficult because of the high titres of HBsAg in many of these cases. Although 
there was in this study a trend towards higher HBsAg titres in the chronic hepatitis group this relationship did not apply to the entire series of blood donors (Woolf et al, 1974). Yeung Laiwah (1971) first drew attention to the possibility that antigen in the serum might interfere with detection of cellular immunity in vitro, and we have shown in both acute and chronic hepatitis that when the titre of HBsAg in the serum exceeds that used in the leucocyte migration test, sensitization cannot usually be demonstrated (Lee, Mitchell, Reed, Vahrman, Zuckerman, Eddleston, and Williams, 1974; Lee et al, 1975). However, in serial studies in such cases, inhibition of leucocyte migration has been observed when the antigen titre has fallen.

If there is, as these results suggest, an appropriate cellular immune response to $\mathrm{HBsAg}$ in the patients who develop chronic liver disease, why does the virus infection persist? Little is known about the role of humoral antibody in the recovery from hepatitis B infection but we have argued elsewhere (Eddleston and Williams, 1974) that a defect in the production of antibody to HBsAg would allow virus particles to penetrate uninfected hepatocytes and establish a cycle of infection, in spite of the destruction by sensitized lymphocytes of those hepatocytes in which the virus had previously replicated. This continuous destruction of infected cells would explain the relatively small number of hepatocytes which can be shown to contain $\mathrm{HBsAg}$ when liver biopsies from patients with antigen-positive active chronic hepatitis have been examined by immunofluorescent techniques (Hadziyannis et al, 1972). In contrast, in healthy carriers, ie, those without histological evidence of liver disease, where both cellular and humoral responses to the antigen are absent there are large numbers of cells with HBsAg in the cytoplasm.

We have previously shown that sensitization to the liver-specific lipoprotein is a frequent finding in active chronic hepatitis (Lee et al, 1974), whether or not HBsAg is present in the serum. Recent evidence suggests that this reaction is not just a secondary phenomenon to liver damage but may be important in its pathogenesis. The lipoprotein is a normal constituent of the hepatocyte cell membrane and rabbits immunized with the human antigen develop lesions in the liver closely resembling chronic aggressive hepatitis (Meyer zum Büschenfelde, Kossling, and Miescher, 1972). Furthermore, peripheral blood lymphocytes from patients who show sensitization to the lipoprotein are cytotoxic to isolated hepatocytes (Thomson, Cochrane, McFarlane, Eddleston, and Williams, 1974). In the present study, the finding of a cellular immune response to this antigen correlated closely with both the presence of an elevated serum aspartate aminotransferase level and with histological changes of chronic persistent or chronic aggressive hepatitis.

The immune response to the liver-specific antigen may be initiated by T-lymphocytes reacting with viral antigens on the surface of infected hepatocytes. The importance of a T-cell response to viral antigenic determinants in promoting an autoimmune reaction has been emphasized by Allison, Denman, and Barnes (1971). This would explain the close association between the immune responses to $\mathrm{HBsAg}$ and the liver-specific antigen. In the absence of a T-cell response to $\mathrm{HBs} A g$, as in healthy carriers, there would be no autoimmune reaction and no liver damage. In contrast, the development of an appropriate T-cell response to $\mathrm{HBsAg}$ would promote an autoimmune response to the lipoprotein membrane antigen which would be cytotoxic to normal hepatocytes, as we have been able to demonstrate in vitro (Thomson et al, 1974), and would continue as long as the virus infection persisted.

We thank Miss Helen Cullens and Miss Barbara Wocjicka for their skilful technical assistance, Dr I. G. McFarlane for the preparation of liver-specific lipoprotein, Professor J. M. Evanson for his support and encouragement and Dr E. Tapp and Dr J. S. Whittaker for interpretation of the liver histology. The work was supported by the Wellcome Trust. W.M.L. was in receipt of an Eli Lilly fellowship from the American College of Physicians and W.D.R. of the Raine Travelling Scholarship from the University of Western Australia.

\section{References}

Allison, A. C., Denman. A. Mí., and Barnes, R. D. (1971). Cooperating and controlling functions of thymus-derived lymphocytes in relation to autoimmuntiy. Lancet, 2, 135-140.

Dudley, F. J., Fox, R. A., and Sherlock, S. (1972). Cellular immunity and hepatitis-associated, Australia antigen liver disease. Lancet, 1, 723-726.

Eddleston, A. L. W. F., McFarlane, I. G., Mitchell, C. G., Reed, W. D., and Williams, R. (1973). Cell-mediated immune response in primary biliary cirrhosis to a protein fraction from human bile. Brit. med. J., 4, 274-276.

Eddleston, A. L. W. F., and Williams, R. (1974). Inadequate antibody response to $\mathrm{HBAg}$ or suppressor T-cell defect in development of active chronic hepatitis. Lancet, 2, 1543-1545.

Giustino, V., Dudley, F. J., and Sherlock, S. (1972). Thymus dependent lymphocyte function in patients with hepatitis-associated antigen. Lancet, 2, 850-853.

de Groote, J., Desmet, V. J., Gedigk, P., Korb, G., Popper, H., Poulsen, H., Scheuer, P. J., Schmid, M., Thaler, H., Uehlinger, E., and Wepler, W. (1968). A classification of chronic hepatitis. Lancet, 2, 626-628.

Hadziyannis, S., Vissoulis, C., Moussouros, A., and Afroudakis, A. (1972). Cytoplasmic localization of Australia antigen in the liver. Lancet, 1, 976-979.

Lee, W. M., Mitchell, C. G., Reed, W. D., Vahrman, J., Zuckerman, A. J., Eddleston, A. L. W. F., and Williams, R. (1974). Cellmediated immunity to hepatitis $B$ antigen and to liver-specific 
antigen in acute viral hepatitis type B. (Abstr.) Digestion, 10, 328.

Lee, W. M., Reed, W. D., Mitchell, C. G., Galbraith, R. M., Eddleston, A. L. W. F., Zuckerman, A. J., and Williams, R. (1975). Cellular and humoral immunity to the hepatitis B surface antigen in active chronic hepatitis. Brit. med. J., 1, 705708.

Meyer zum Büschenfelde, K. H., Kossling, F. K., and Miescher, P. A. (1972). Experimental chronic active hepatitis in rabbits following immunization with human liver proteins. Clin. exp. Immunol., 11, 99-108.

Nielsen, J. O., Reinicke, V., Dietrichson, O., Andersen, V., Thomsen, M., and Andersen, E. (1973). Immunological studies of Australia antigen carriers with and without liver diseases. Clin. exp. Immunol., 15, 9-16.

Reed, W. D., Eddleston, A. L. W. F., Stern, R. B., Williams, R., Zuckerman, A. J., Bowes, A., and Earl, P. M. (1973). Detec- tion of hepatitis-B antigen by radioimmunoassay in chronic liver disease and hepatocellular carcinoma in Great Britain. Lancet, 2, 690-694.

Reed, W. D., Mitchell, C. G., Eddleston, A. L. W. F., Lee, W. M., Williams, R., and Zuckerman, A. J. (1974). Exposure and immunity to hepatitis-B virus in a Liver unit. Lancet, 1, $581-583$.

Thomson, A. D., Cochrane, A. M. G., McFarlane, I. G., Eddleston, A. L. W. F., and Williams, R. (1974). Lymphocyte cytotoxicity to isolated hepatocytes in chronic active hepatitis. Nature (Lond.), 252, 721-722.

Woolf, I. L., Boyes, B. E., Jones, D. M., Whittaker, J. S., Tapp, E. MacSween, R. N. M., Renton, P. H., Stratton, F., and Dymock, I. W. (1974). Asymptomatic liver disease in hepatitis B antigen carriers. J. clin. Path., 27, 348-352.

Yeung Laiwah ,A. A. C. (1971). 'Lymphocyte transformation by Australia antigen. Lancet, $2,470-471$. 